Research paper

\title{
Molecular, biological, and morphometric comparisons between different geographical populations of Rhipicephalus sanguineus sensu lato (Acari: Ixodidae)
}

\author{
Gustavo S. Sanches a, ${ }^{\mathrm{b}}$, Patrícia M. Évora ${ }^{\mathrm{b}}$, Atílio J. Mangold ${ }^{\mathrm{c}}$, Sattaporn Jittapalapong ${ }^{\mathrm{d}}$, \\ Alina Rodriguez-Mallon ${ }^{\mathrm{e}}$, Pedro E.E. Guzmán ${ }^{\mathrm{e}}$, Gervásio H. Bechara ${ }^{\mathrm{b}, \mathrm{f}, * \text {, }}$ \\ Maria I. Camargo-Mathias ${ }^{\text {a }}$ \\ a Instituto de Biociências, Departamento de Biologia, Unesp Campus Rio Claro, Av. 24 A, no. 1515, 13506-900 Rio Claro, SP, Brazil \\ ${ }^{\mathrm{b}}$ Laboratório de Imunopatologia, Departamento de Patologia Veterinária, Unesp Campus Jaboticabal, Via de Acesso Paulo Donato Castellane, s/n, \\ 14884-900 Jaboticabal, SP, Brazil \\ ${ }^{c}$ Instituto Nacional de Tecnología Agropecuaria, Estación Experimental Agropecuaria Rafaela, Santa Fe, Argentina \\ ${ }^{\mathrm{d}}$ Faculty of Veterinary Medicine, Kasetsart University, Bangkok, Thailand \\ e Centro de Ingeniería Genética y Biotecnología-CIGB, Habana, Cuba \\ f Pontifícia Universidade Católica do Paraná-PUCPR, Rua Imaculada Conceição, 1155 Curitiba, PR, Brazil
}

\section{A R T I C L E I N F O}

\section{Article history:}

Received 19 August 2015

Received in revised form 4 November 2015

Accepted 12 November 2015

\section{Keywords:}

Rhipicephalus sanguineus

Genetic analysis

Morphometry

Taxonomy

\begin{abstract}
A B S T R A C T
In this study, different geographical populations of Rhipicephalus sanguineus sensu lato were compared by molecular, biological, and morphometric methods. Phylogenetic trees were constructed using $12 \mathrm{~S}$ and 16S rDNA sequences and showed two distinct clades: one composed of ticks from Brazil (Jaboticabal, SP), Cuba (Havana) Thailand (Bangkok) and the so-called "tropical strain" ticks. The second clade was composed of ticks from Spain (Zaragoza), Argentina (Rafaela, Santa Fe) and the so-called "temperate strain" ticks. Morphometric analysis showed good separation between females of the two clades and within the temperate clade. Males also exhibited separation between the two clades, but with some overlap. Multiple biological parameters revealed differences between the two clades, especially the weight of the engorged female. These results confirm the existence of at least two species under the name " $R$. sanguineus".
\end{abstract}

(C) 2015 Elsevier B.V. All rights reserved.

\section{Introduction}

The "Rhipicephalus sanguineus complex" includes 17 species: Rhipicephalus aurantiacus Neumann, 1907; Rhipicephalus bergeoni Morel and Balis, 1976, Rhipicephalus boueti Morel, 1957; Rhipicephalus camicasi Morel, Mouchet and Rodhain, 1976; Rhipicephalus guilhoni Morel and Vassiliades, 1963; Rhipicephalus leporis Pomerantzev, 1946; Rhipicephalus moucheti Morel, 1965; Rhipicephalus pumilio Schulze, 1935; Rhipicephalus pusillus Gil Collado, 1936; Rhipicephalus ramachandrai Dhanda, 1966; Rhipicephalus rossicus Yakimov and Kol-Yakimova, 1911; R. sanguineus sensu stricto (s.s.); Rhipicephalus schulzei Olenev, 1929; Rhipicephalus sulcatus Neumann, 1908; Rhipicephalus tetracornus Kitaoka and Suzuki, 1983;

\footnotetext{
* Corresponding author at: Pontifícia Universidade Católica do Paraná-PUCPR, Rua Imaculada Conceição, 1155 Curitiba, PR, Brazil.

E-mail address: gervasio.bechara@pucpr.br (G.H. Bechara).
}

Rhipicephalus turanicus Pomerantzev, 1940; and Rhipicephalus ziemanni Neumann, 1904. Some of these are closely related, morphologically similar, and, consequently, have been misidentified (Walker et al., 2000 reviewed in Dantas-Torres and Otranto, 2015).

Historically, $R$. sanguineus sensu stricto (s.s) is the most controversial species in the " $R$. sanguineus complex". Originally, was classified as Ixodes sanguineus by Latreille (1806) and later transferred to the genus Rhipicephalus by Koch (1844). Moreover, the original description does not provide a definition of the morphological basis for the species. According to Nava et al. (2015), in light of these data, $R$. sanguineus s.s. could be relegated to a nomen nudum. Following this description, many species and subspecies belonging to the " $R$. sanguineus complex" were synonymized as $R$. sanguineus s.s. around the world (Camicas et al., 1998; Walker et al., 2000). The type locality is Gallia (France). In this context, Guglielmone et al. (2014) deemed $R$. sanguineus s.s. a Palearctic species, considering all other records of this species around the world as speculative. 
Over the last decade, some studies started to indicate that what was known until the moment as $R$. sanguineus (s.s.) could be represented by more than one species. Szabó et al. (2005) and Oliveira et al. (2005) suggested that the taxon of $R$. sanguineus would be composed of at least two morphologically and genetically distinct strains in the Neotropics. Moraes-Filho et al. (2011) proposed a so-called "southern lineage," located in temperate localities (Argentina, Uruguay, Chile, Italy, and south Brazil), and a "northern lineage," located in tropical and subtropical localities (Brazil, Paraguay, Colombia, South Africa, Mozambique, and northern Argentina). Nava et al. (2012) observed these same lineages in the Southern Cone of South America. Dantas-Torres et al. (2013) also recognized these lineages in the Old World and suggested the possibility of other genetic lineages under the name " $R$. sanguineus. " Despite these findings, the taxonomy status of this species is far from resolved. Along this line, a consensual redescription of $R$. sanguineus s.s. and a description of the other(s) species under this name are required, after an exhaustive worldwide revision of this species complex (Dantas-Torres et al., 2013). However, morphological variations within the same genetic strain of $R$. sanguineus (Pegram et al., 1987; Dantas-Torres et al., 2013) are quite common, which is the main current taxonomic issue. Levin et al. (2012) and Gray et al. (2013) drew attention to the need of studies addressing morphology, genetic and biological aspects, considering variations of these ticks over a large geographical range.

In view of these data, the present study aimed to compare, genetically, morphometrically and biologically, the different geographical populations of $R$. sanguineus sensu lato (s.l.) from the so-called tropical (Brazil, Cuba, and Thailand) and temperate (Argentina and Spain) strains. The results obtained in this study may contribute to a better understanding of $R$. sanguineus' biosystematic status.

\section{Materials and methods}

\subsection{Ticks}

The specimens used in this study were obtained from colonies established at the Department of Veterinary Pathology, Universidade Estadual Paulista-UNESP, Campus of Jaboticabal, São Paulo State, Brazil from isolates made in Cuba, Thailand, Argentina and Spain (Table 1 and Fig. 1). The identification of isolates was confirmed by each provider according to Walker et al. (2000). To maintain colonies, pools of ticks were periodically fed on 5-8 month-old New Zealand white rabbits. Non parasitic stages were kept under controlled conditions to $27^{\circ} \mathrm{C}$, $80 \%$ relative humidity, and 12-h photoperiod for tropical strains and to $20^{\circ} \mathrm{C}, 80 \%$ relative humidity, and 12-h photoperiod for temperate strains.

\subsection{Molecular analysis}

Phylogenetic analyses were performed from mitochondrial DNA of ticks from the colonies described in Table 1. A sample of $R$. sanguineus from La Libertad, Magdalena, Colombia $\left(4^{\circ} 35^{\prime} \mathrm{N} ; 74^{\circ} 04^{\prime} \mathrm{W}\right)$, kindly provided by Dr. Efrain Benavides Ortiz (University of La Salle, Bogotá, Colombia), was added to the molecular analysis. From each strain, DNA extraction was separately performed using two individual adult ticks, according to a previously described protocol (Mangold et al., 1998). A 380 base pair (bp) fragment of the 12S rDNA gene and a $460 \mathrm{bp}$ fragment of the $16 \mathrm{~S}$ rDNA gene were amplified by PCR using previously described primers (Black and Piesman, 1994; Szabó et al., 2005). Amplified DNA was purified using a Wizard PCR Preps DNA Purification System (Promega) according to the manufacturer's recommendations. Purified PCR products were submitted for sequencing using an ABI PRISM Dye Terminator Cycle Sequencing Ready Reaction kit in an Applied Biosystems 373A gene sequencer. Sequences were manually edited using Bioedit Sequence Aligment Editor (Hall, 1999) and aligned using Clustal W software (Larkin et al., 2007). Additionally, GenBank available Rhipicephalus spp. 12S and 16S rDNA partial sequences were included in the molecular analysis. Only sequences published in reference's studies or unpublished sequences with host and geographical origin information were used. The GenBank accession numbers of these sequences and the geographical origins are presented in the phylogenetic trees. GenBank available partial 12S rDNA(AF150034) and 16S rDNA (L34307) sequences of Hyalomma marginatum were used as outgroups. The nucleotide sequences obtained in this study were deposited in the GenBank database (12S rDNA: KC018070, KC018072, KC018074, KC018075, KC018076; 16S rDNA: JX997387, JX997389, JX997390, JX997391, JX997393). The percentage of nucleotide variation among sequences of a given species was calculated by pairwise comparison (Kimura 2-parameter model) using the MEGA 5.0 software (Tamura et al., 2007). The formula $D=1-(\mathrm{M} / \mathrm{L})$ was used to compare the sequences obtained in this work with the Rhipicephalus spp. consensus sequence. In this formula $D$ is the sequence difference, $M$ is the number of alignment positions at which the two sequences have a base in common and $L$ is the total number of alignment positions over which the two sequences are compared (Chilton et al., 1995). The maximum likelihood (ML) method was used to make the phylogenetic analysis, which was also conducted in MEGA 6.0 Program. ML trees were generated using the Tamura-Nei substitution model with uniform rates among sites. The partial deletion option was used for gap analysis in MP trees with $95 \%$ of site coverage cutoff. A bootstrap test with 1000 replications was applied to estimate the confidence of the tree branching patterns.

\subsection{Morphometric comparison}

For morphometric comparisons, 10 couples of each $R$. sanguineus strain were slide-mounted according to the method of Famadas et al. (1996). Measurements were performed using a MC80DX light microscope coupled with a digital camera (Leica Microsystems). The following characteristics were measured: basis capituli (length and width); palps (length); tarsus I (length and width); dorsal scutum (length and width); idiosoma (length from scapular apices to posterior idiosomal margin and width); spiracular plates (length and width); and male adanal plates (length and width at base). All measurements are in millimeters and expressed as mean \pm standard deviation. Voucher tick specimens were deposited in the Laboratory of Imunopathology, Department

Table 1

Rhipicephalus sanguineus strains used in the present study.

\begin{tabular}{|c|c|c|c|}
\hline Species & Location & Coordinates & Provided by \\
\hline 1. $R$. sanguineus s.l. & Havana, Cuba & $23^{\circ} 07^{\prime} \mathrm{N} ; 82^{\circ} 22^{\prime} \mathrm{W}$ & Dr. Alina R. Mallon \\
\hline 2. R. sanguineus s.l. & Jaboticabal, SP, Brazil & $21^{\circ} 15^{\prime} \mathrm{S} ; 48^{\circ} 18^{\prime} \mathrm{W}$ & Dr. Gervásio H. Bechara \\
\hline 3. $R$. sanguineus s.l. & Bangkok, Thailand & $7^{\circ} 59^{\prime} \mathrm{N} ; 98^{\circ} 20^{\prime} \mathrm{E}$ & Dr. Sathaporn Jittapalapong \\
\hline 4. $R$. sanguineus s.l. & Rafaela, Santa Fe, Argentina & $31^{\circ} 15^{\prime} \mathrm{S} ; 61^{\circ} 29^{\prime} \mathrm{W}$ & Dr. Santiago Nava \\
\hline 5. $R$. sanguineus s.l. & Zaragoza, Spain & $41^{\circ} 39^{\prime} \mathrm{N} ; 00^{\circ} 52^{\prime} \mathrm{W}$ & Dr. Agustín Estrada-Peña \\
\hline
\end{tabular}



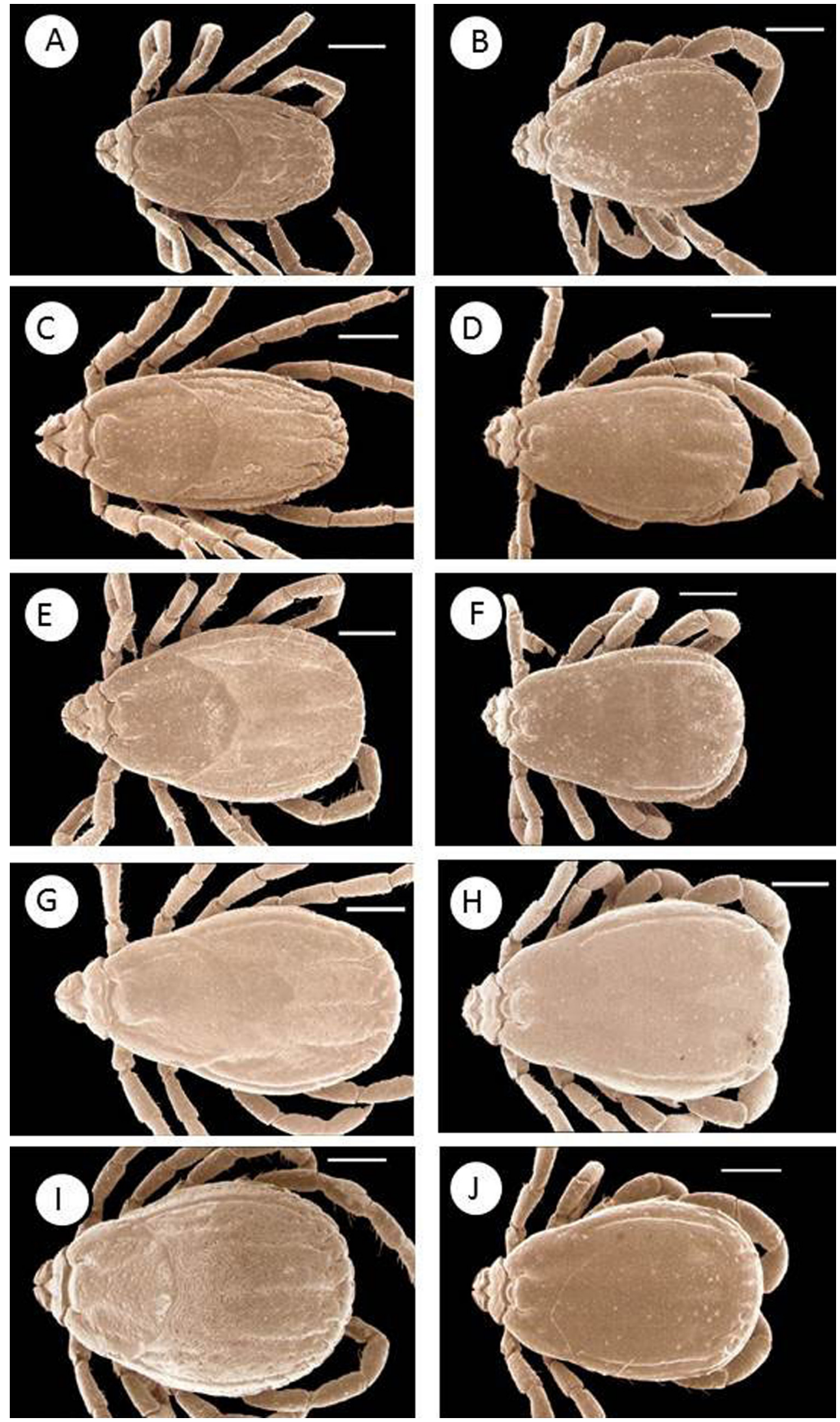

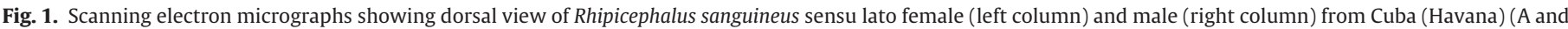
B); Brazil (Jaboticabal, SP) (C and D); Thailand (Bangkok) (E and F); Argentina (Rafaela, Santa Fe) (G and H) and Spain (Zaragoza) (I and J). Scale bars: $100 \mu$ m. 


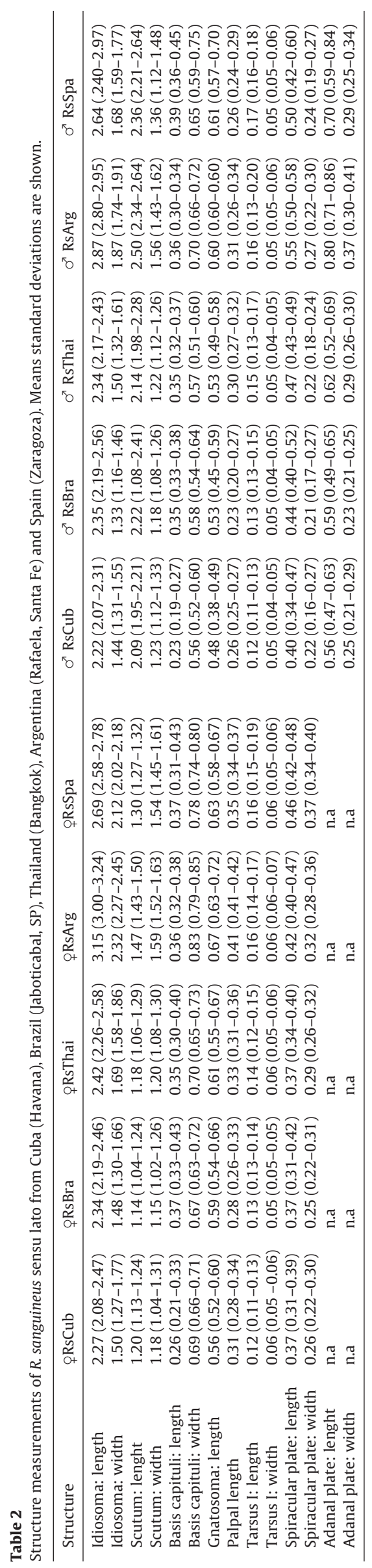

of Veterinary Pathology, Sao Paulo State University-UNESP, Campus of Jaboticabal, Sao Paulo State, Brazil.

\subsection{Comparison of feeding and reproductive parameters}

Ten New Zealand white rabbits, 5-8 months old, weighing approximately $1 \mathrm{~kg}$ and certified to have no previous history of tick infestation, were used as hosts. Each host was fitted with five feeding chambers, fixed with synthetic glue (Brascoplast ${ }^{\circledR}$, Brascola Ltda., Brazil) on the dorsal region of the animal as described by Bechara et al. (1995). Ten couples of each $R$. sanguineus population (Brazil, Cuba, Thailand, Argentina, and Spain) were confined in the separated feeding chambers. The chambers were examined daily, and engorged detached females were weighed individually and kept under constant temperature and relative humidity, as described previously. The following data were recorded: tick yield, engorged female and egg mass weights, engorging, pre-oviposition and incubation periods, larval hatchability rate, and efficiency rate of female ticks in converting their food reservoir to eggs. The larval hatchability rate was assessed according to the method used by Szabó et al. (1995): briefly, the larval hatching rate for each tick was obtained by calculating the mean value of visual double-blind evaluation, separately performed by three persons. Procedures performed in this study were approved by the ethics committee on animal experimentation (CEUA/UNESP 02.287/10).

\subsection{Data analyses}

Morphometric variables of the ticks included in this study were used to carry out a principal component analysis (PCA) based on Pearson correlation matrix, in order to perform a comparison of the specimens among each geographical population. Data from the feeding and reproductive parameters of each population were compared using one-way analysis of variance (ANOVA) followed by Tukey's multiple comparison test; a $p$-value $<0.05$ was considered statistically significant. Statistical analyses were performed using GraphPad Prism 5.0 software.

\section{Results}

\subsection{Phylogenetic analysis}

\subsubsection{Partial $12 S$ rDNA sequences}

The tree generated by ML (Fig. 2) shows $R$. sanguineus from Brazil, Cuba, Colombia and Thailand closely related to $R$. sanguineus from Paraguay, Peru, tropical areas of Argentina, Mozambique, Taiwan, China, Saint Kitts, Mexico and Guatemala. $R$. sanguineus from Spain appeared clustered with $R$. sanguineus from Portugal, USA, Israel, Switzerland, Uruguay and temperate areas from Argentina. The nucleotide divergence between $R$. sanguineus sequences from Brazil (Jaboticabal, SP), Cuba (Havana), Colombia (La Libertad, Magdalena), and Thailand (Bangkok) and those from the tropical lineages of America (Peru, Paraguay, Guatemala, Mexico, Saint Kitts, and Argentina-Ingeniero Juarez [Formosa] and Dragones [Salta] localities) ranged from 0.0 to $0.7 \%$. The nucleotide divergence between $R$. sanguineus from Spain and sequences from temperate lineages (Uruguay and Argentina-Formosa [Formosa], Taco Pozo [Chaco], Bernardo de Irigoyen [Misiones], Bahia Blanca [Buenos Aires], and Rafaela [Santa Fe] localities) was $0.2 \%$. The nucleotide divergence between sequences from these tropical and temperate groups ranged from 6.7 to $7.2 \%$. The nucleotide differences of $R$. sanguineus (s.l.) sequences within some regions of the USA (California, Arizona) ranged $0.7 \%$, and they were different from those from tropical and temperate lineages by $6.9-7.7 \%$ and $0.7-$ $1.7 \%$, respectively. 


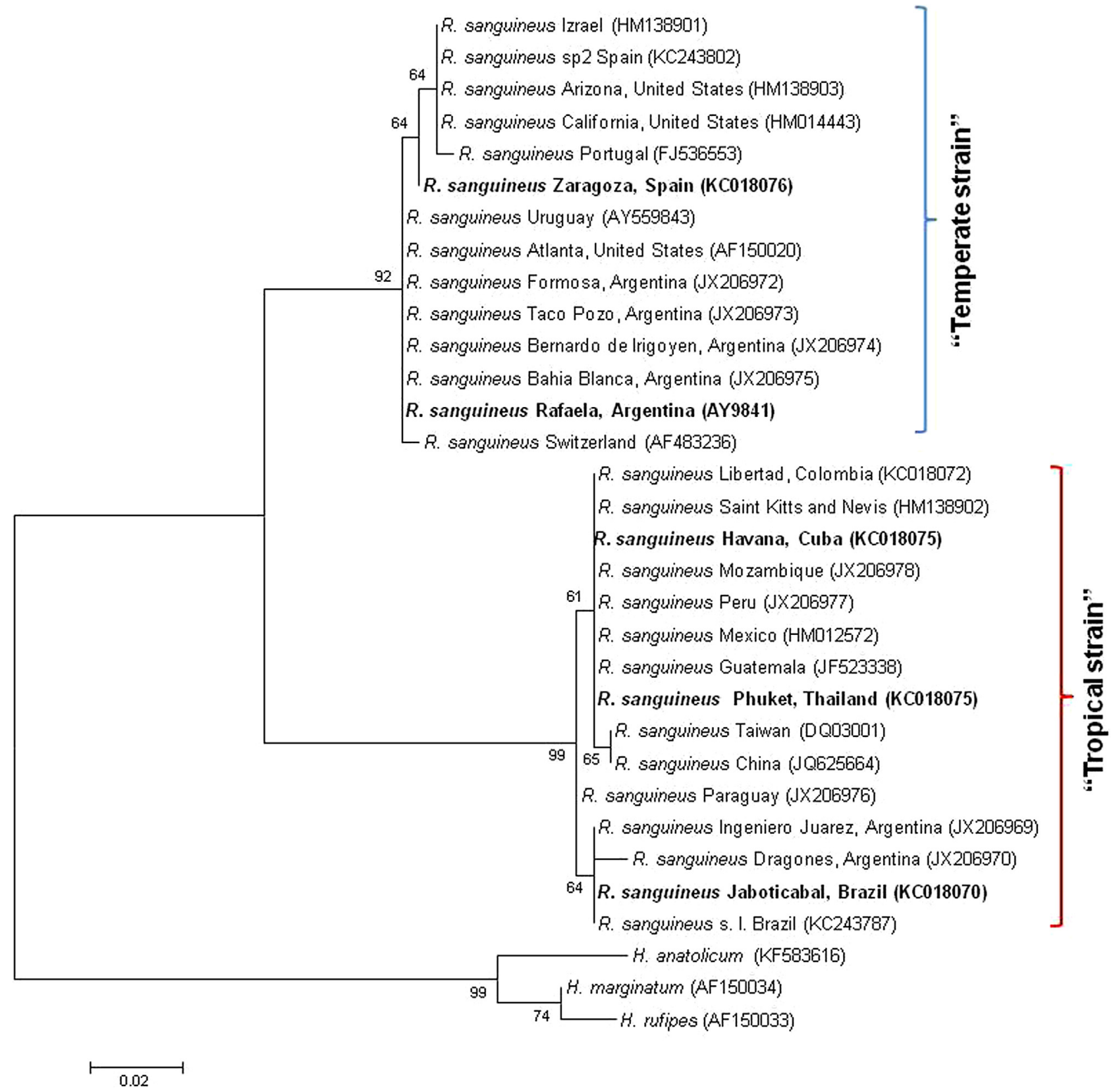

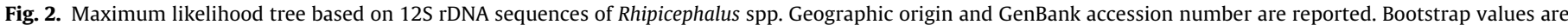
based on 1000 replicates and only bootstraps $>50 \%$ are indicated.

\subsubsection{Partial $16 \mathrm{~S} r \mathrm{DNA}$ sequences}

The tree generated by ML (Fig. 3 ) shows that $R$. sanguineus from Brazil, Cuba, Colombia, and Thailand appeared closely related to $R$. sanguineus from Mozambique, South Africa, Taiwan, and tropical areas of Argentina. On the other hand, $R$. sanguineus from Spain appeared clustered with $R$. sanguineus from France, Germany, Chile, Uruguay, and temperate areas from Argentina.

The nucleotide divergence between $R$. sanguineus sequences from Brazil (Jaboticabal, SP), Cuba (Havana), Colombia (La Libertad, Magdalena), and Thailand (Bangkok) and those from tropical lineages from America (Tropical A: Brazil-Uberlândia, Cuiabá (MT), Sinop (MT), Guarantã do Norte (MT), Recife (PE), Fortaleza (CE), Cumbuco (CE), Tropical B: Brazil-Garopaba (SC), Seropédica (RJ), Itabira (MG), Nova Venecia (ES), João Pessoa (PB), Teresina (PI), Macapá (AP), Porto Velho (RO); Venezuela-Mérida, Los Roques Archipelago; Panamá-Panamá
City; Costa Rica-San José; México-Linares; Argentina-Ingieniero Juares (Formosa), Dragones (Salta); Colombia-Los Córdobas (Cordoba); Paraguay-Assunción) ranged from 0.0 to $0.5 \%$. The nucleotide divergence between $R$. sanguineus from Spain and sequences from temperate lineages (Uruguay-Montevideo (Montevideo), Salto (Salto), José Ignacio (Maldonado); Brazil-Santa Maria (RS); Argentina-Villa San José (Santa Fe), San Cristobal (Santa Fe), Rafaela (Santa Fe), El Dorado (Misiones), Bernardo de Irigoyen (Misiones), Corrientes (Corrientes), Formosa (Formosa), Salta (Salta), Metan (Salta), Malargue (Mendoza), San Salvador de Jujuy (Jujuy), Taco Pozo (Chaco), Puerto Madryn (Chubut), Bahia Blanca (Buenos Aires), Ciudad de Buenos Aires (Buenos Aires), San Juan (San Juan); Chile-Eastern Island, Santiago, Viña del Mar localities) ranged from 0.3 to $1.0 \%$. The nucleotide divergence between sequences from these tropical and temperate groups ranged from 4.7 to $6.3 \%$. 


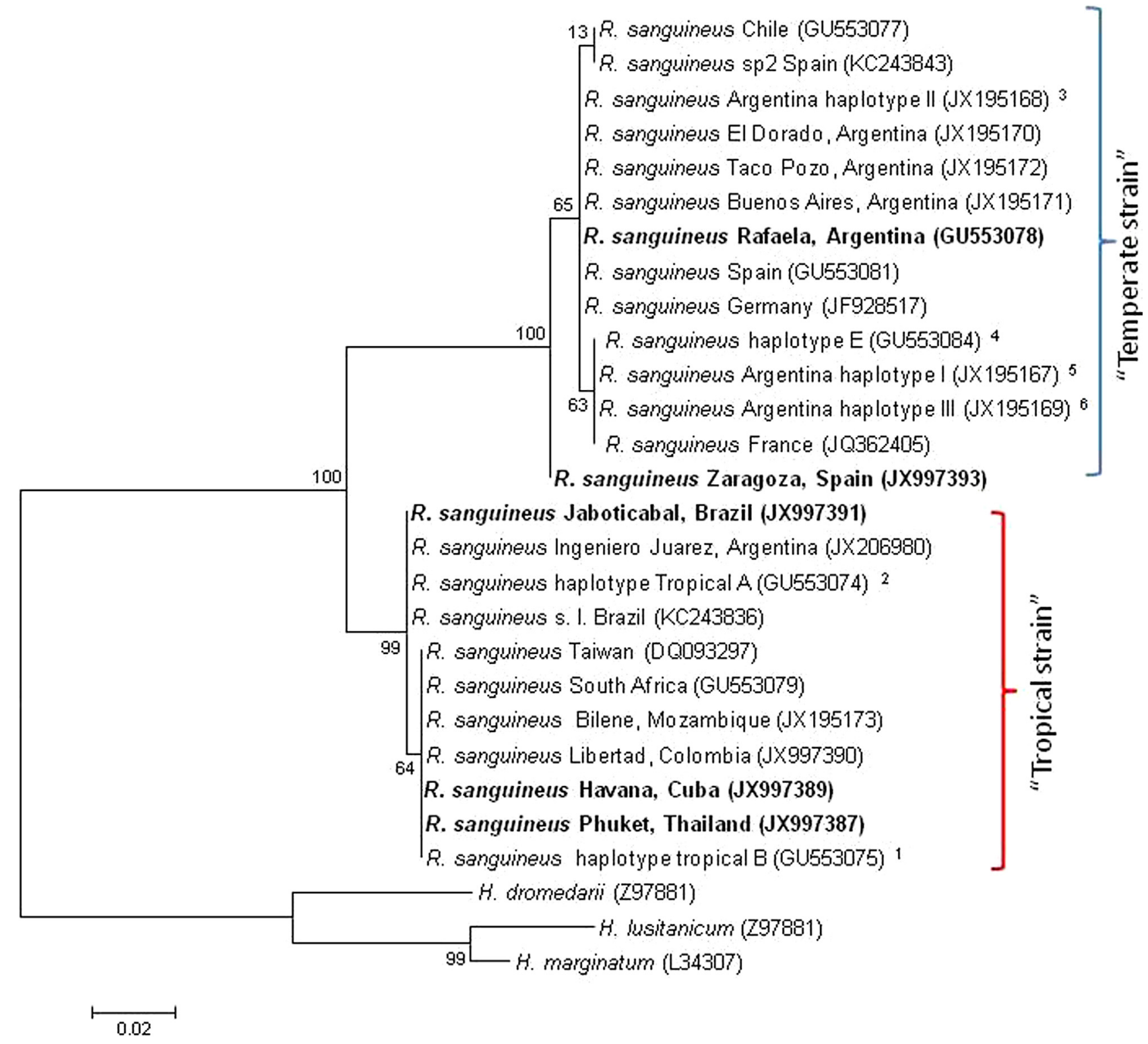

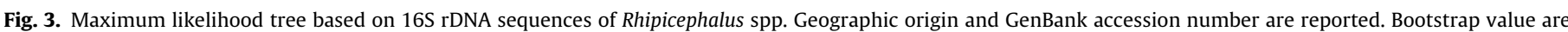

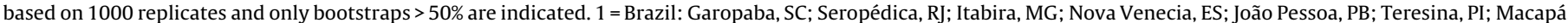

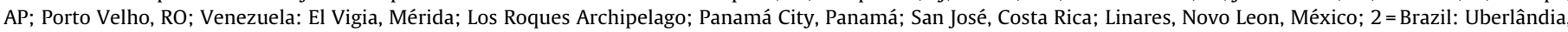

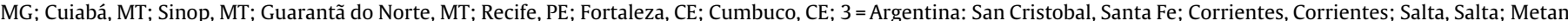

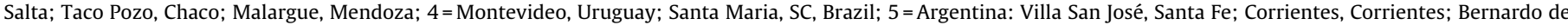

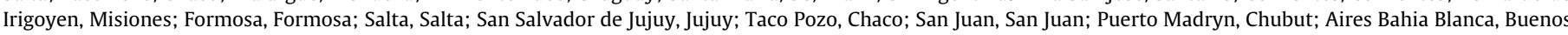

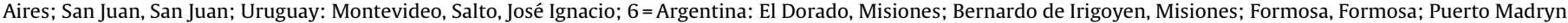
Chubut.

\subsection{Morphometric comparison}

The measurements of each structure are presented in Table 2 and the PCA of female and male are presented in Figs. 4 and 5, respectively.

The PCA performed with morphometric characters of female ticks showed a clear separation between ticks from the tropical and the temperate groups and a separation within the temperate group (Argentina and Spain). The first principal component (explaining $69.66 \%$ of total variance) is loaded most heavily by length of idiosoma, width of idiosoma and width of scutum. The second component (explaining $10.31 \%$ of total variance) is mainly loaded with length of basis capituli and width of tarsus I.

The PCA performed with morphometric characters of male ticks also showed a separation between ticks from the tropical and the temperate groups but with some overlap between then. The first principal component (explaining $59.46 \%$ of total variance) is loaded most heavily by length of idiosoma, width of idiosoma and width of basis capituli. The second principal component (explaining $11.07 \%$ of total variance) is mainly loaded with length of basis capituli.

\subsection{Comparison of feeding and reproductive parameters}

Statistical analysis of engorged female weight and egg mass weight revealed that populations from the tropical strain ( $R$. sanguineus from Jaboticabal, Cuba, and Thailand) were significantly different from the temperate strain ( $R$. sanguineus from Argentina and Spain). No significant differences were observed within the tropical and temperate groups for these parameters, although, in the tropical group, engorged $R$. sanguineus females from Cuba 


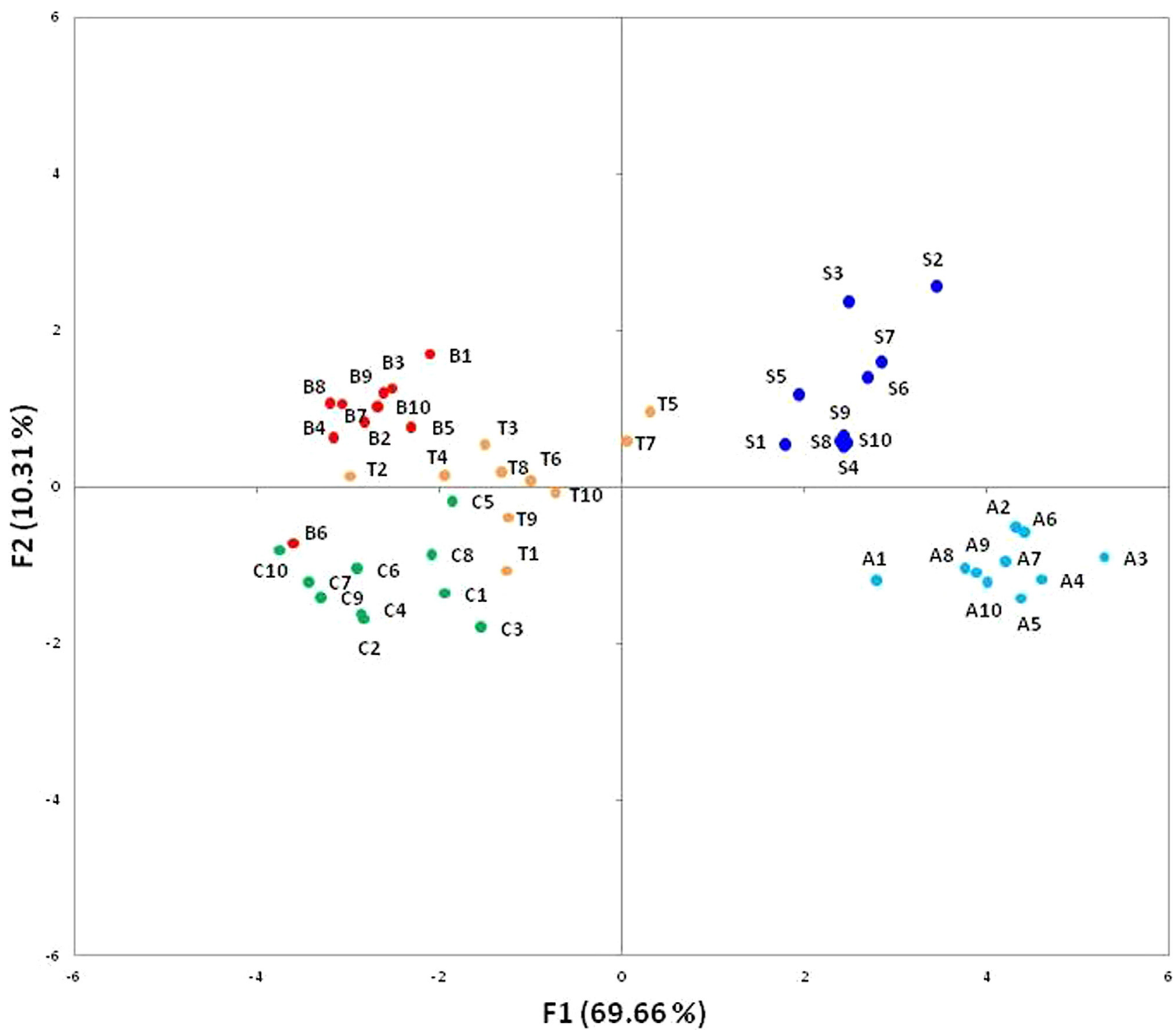

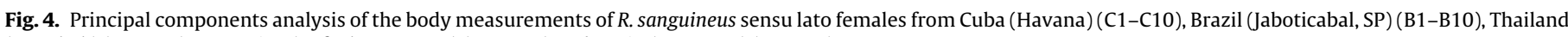
(Bangkok) (T1-T10), Argentina (Rafaela, Santa Fe) (A1-A10) and Spain (Zaragoza) (S1-S10).

Table 3

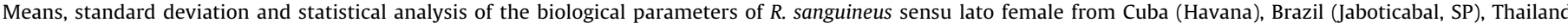
(Bangkok), Argentina (Rafaela, Santa Fe) and Spain (Zaragoza) fed on tick-bite naive rabbits.

\begin{tabular}{|c|c|c|c|c|c|}
\hline Parameter & Rs Cub & Rs Braz & Rs Thai & Rs Arg & Rs Spa \\
\hline EFW & $85.9 \pm 30.23^{a}$ & $132.3 \pm 25.13^{a}$ & $166.8 \pm 29.96^{a}$ & $285.1 \pm 68.78^{b}$ & $332.2 \pm 123.29^{b}$ \\
\hline $\mathrm{EP}$ & $10.5 \pm 1.27^{\mathrm{a}}$ & $10.7 \pm 0.82^{a}$ & $9.9 \pm 1.57^{\mathrm{a}}$ & $10.4 \pm 2.59^{a}$ & $16.2 \pm 3.57^{b}$ \\
\hline EMW & $45.7 \pm 8.35 \mathrm{a}$ & $66.2 \pm 16.39^{a}$ & $105.6 \pm 24.65^{a}$ & $158.1 \pm 20.98^{b}$ & $164.6 \pm 65.13^{b}$ \\
\hline POP & $4.0 \pm 1.00^{a}$ & $4.3 \pm 1.18^{a}$ & $4.0 \pm 1.00^{\mathrm{a}}$ & $4.00 \pm 0.81^{\mathrm{a}}$ & $2.3 \pm 0.51^{b}$ \\
\hline IP & $20.5 \pm 1.73^{a}$ & $19.3 \pm 1.75^{a}$ & $20.0 \pm 1.41^{a}$ & $21.4 \pm 1.14^{a}$ & $21.8 \pm 0.99^{a}$ \\
\hline LH (\%) & $92.8 \pm 2.16 \mathrm{a}$ & $91.9 \pm 3.78^{a}$ & $95.6 \pm n 3.78^{a}$ & $93.4 \pm 4.21^{a}$ & $92.7 \pm 2.96^{\mathrm{a}}$ \\
\hline ERCE (\%) & 53. $\pm 3.62^{a}$ & $50.0 \pm 8.07^{a}$ & $58.4 \pm 13.30^{a}$ & $50.4 \pm 1.14^{a}$ & $49.0 \pm 6.31^{a}$ \\
\hline Tick yield (\%) & $93.3 \pm 11.54^{\mathrm{a}}$ & $90 \pm 1.14^{a}$ & $96.6 \pm 5.77^{a}$ & $76.6 \pm 15.27^{\mathrm{a}}$ & $90 \pm 10.00^{a}$ \\
\hline
\end{tabular}

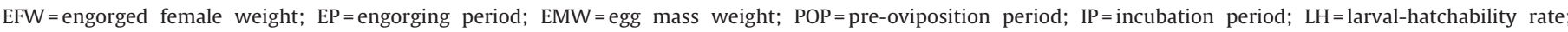
$E R C E=$ efficiency rates of female ticks in converting their food reservoir to eggs. Means in a line followed by the same letter do not differ significantly $(p<0.05)$.

were $35 \%$ and $48 \%$ lighter than $R$. sanguineus from Jaboticabal and Thailand, respectively. In the temperate group, $R$. sanguineus from Spain was approximately 14\% heavier than $R$. sanguineus from Argentina. The engorgement period of $R$. sanguineus females from Spain was significantly longer than those from Brazil, Cuba, Thailand, and Argentina, and the pre-oviposition period was signif- icantly shorter than those from Brazil, Thailand, and Argentina. No significant differences were observed in incubation period, larval hatchability rate, efficiency rate of female ticks in converting their food reservoir to eggs, and tick yield of each strain. The results are presented in Table 3. 


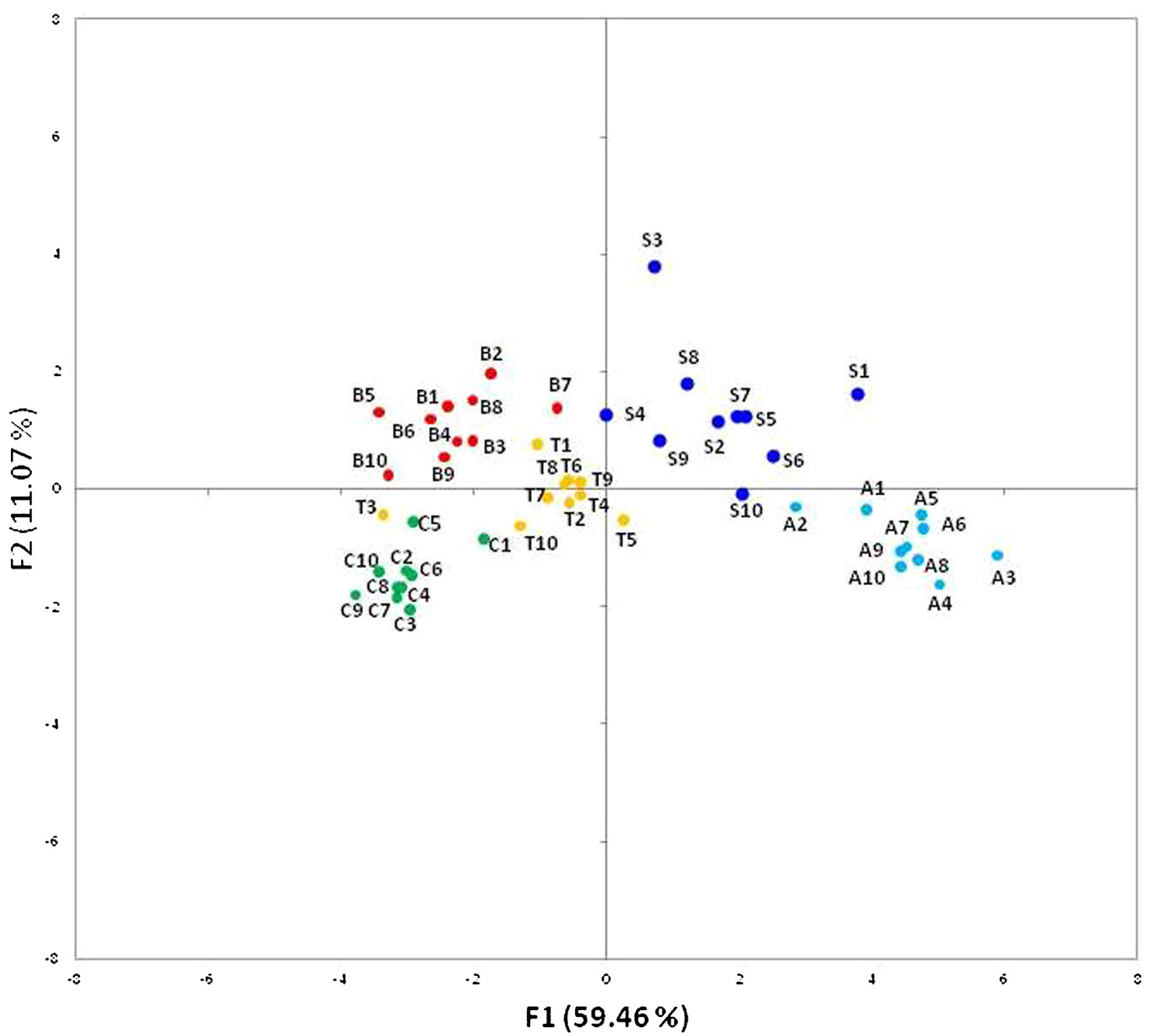

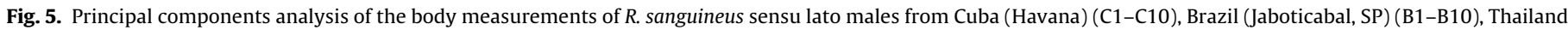
(Bangkok) (T1-T10), Argentina (Rafaela, Santa Fe) (A1-A10) and Spain (Zaragoza) (S1-S10).

\section{Discussion}

The conducted phylogenetic analysis of $16 \mathrm{~S}$ and 12S rDNA sequences from $R$. sanguineus (s.l.) segregated ticks from Brazil (Jaboticabal, SP), Cuba (Havana), Thailand (Bangkok), Argentina (Rafaela, Santa Fe), and Spain (Zaragoza) into two distinct clades. Moraes-Filho et al. (2011), Nava et al. (2012), and Dantas-Torres et al. (2013) also observed these two clades, analyzing $R$. sanguineus specimens in Latin America, the Southern Cone of South America and in the New and Old Worlds, respectively. They proposed the so-called "tropical strain" for the clade composed of tropical and subtropical populations, and the "temperate strain" for the clade composed of temperate populations of $R$. sanguineus ticks. In this context, the sequences of $R$. sanguineus from Brazil (Jaboticabal, SP), Cuba (Havana) and Thailand (Bangkok) were clustered with other tick sequences in the "tropical strain", and R. sanguineus from Argentina (Rafaela, Santa Fe) and Spain (Zaragoza) were clustered with other tick sequences in the "temperate strain". This segregation into different clades indicated the occurrence of two different species under the name " $R$. sanguineus", as previously reported in studies conducted in Brazil, Argentina, the United States, China and Europe (Szabó et al., 2005; Liu et al., 2007; Moraes-Filho et al., 2011; Levin et al., 2012; Nava et al., 2012; Dantas-Torres et al., 2013). According to Nava et al. (2012), the "temperate strain" cluster, formed by $R$. sanguineus from Western Europe and southern South America, probably represents $R$. sanguineus s.s. and the "tropical strain" cluster represents another species that is not the true $R$. sanguineus.

The results obtained with morphometric methods were coherent with those acquired using molecular markers. The tropical group presented small-sized ticks (female idiosomal length $\times$ breadth ranging from $2.08 \times 1.27$ to $2.58 \times 1.86$ ) when compared to ticks belonging to the temperate group (female idiosomal length $\times$ breadth ranging from $2.58 \times 2.02$ to $3.24 \times 2.45$ ). Oliveira et al. (2005), comparing females from Brazil (tropical strain) and Argentina (temperate strain), previously reported this observation. The PCA performed with morphometric characters also showed a clear separation between female ticks from the 
tropical and the temperate groups, mainly loaded with idiosomal length and width and variations of size within the same group were observed. The PCA performed with morphometric characters showed some separation between male ticks from the tropical and the temperate groups, mainly loaded with idiosomal length and width, but with overlap between them. This difference in male and female PCA could be explained by their distinct role in mating and reproduction once that males take only small blood meals in the adult stage (Fairbairn, 1997). Size variations among individual ticks within the same lineage may be explained by phenotypic plasticity. According to West-Eberhard (2003), virtually all organisms can exhibit some degree of plasticity, affected by external conditions. The plasticity phenomena can be classified in different ways (e.g., morphological, physiological, and behavioral), and the external conditions can be understood as diet, population density, temperature, and photoperiod (Minelli and Fusco, 2010).

The analysis of biological parameters showed that engorged females from the temperate strain were statistically heavier than engorged females from the tropical strain, corroborating the differences obtained in the idiosomal size of females. A relationship between feeding and tick body size has been observed in several other tick species (Dietrich et al., 2012). Amin and Sonenshine (1970) and Koch (1986) observed that incomplete feeding of immature stages has been shown to result in smaller adults in Ixodes ricinus, Dermacentor variabilis, Hyalomma asiaticum and Amblyomma americanum. According to Obenchain et al. (1980), the egg mass laid is directly related to the female engorged weight, and female engorged weight is directly related to unfed tick size.

Although no significant difference were observed within the tropical and temperate groups for the female engorged weight, in the tropical group, $R$. sanguineus females from Cuba were 35\% and $48 \%$ lighter than those from Jaboticabal and Thailand, respectively, and in the temperate group, $R$. sanguineus from Spain was approximately $14 \%$ heavier than those from Argentina.

Speybroeck et al. (2002, 2004), studying the $R$. appendiculatus complex in Africa, hypothesized that body size is related to diapausing intensity. Different seasonal activity patterns are observed at different latitudes. Near the equator, ticks usually feed throughout the year and the quantity of ticks vary less in time than at higher latitudes. The size of ticks also tends to be smaller near the equator than the size of ticks at higher latitudes. This finding helps explain, at least in parts, the variation in tick size that we observed between the two lineages.

Finally, our results confirmed that $R$. sanguineus s.l. is represented by at least two genetic lineages that are biologically and morphometrically different. Furthermore, variations within the same lineage were observed and make the morphology-based classification of these tick species a more difficult task.

\section{Acknowledgments}

We would like to thank the Fundação de Amparo à Pesquisa do Estado de São Paulo (FAPESP) for the financial support and scholarship (Processes \#2010/00415-8 and \#2013/10394-6). M.I. Camargo-Mathias and G.H. Bechara are recipients of academic career research fellowships from the Conselho Nacional de Desenvolvimento Científico e Tecnológico (CNPq). We also thank Dr. Santiago Nava (Instituto Nacional de Tecnología Agropecuaria, Estación Experimental Agropecuaria Rafaela, Santa Fe, Argentina) and Professor Agustin Estrada-Pena (Universidad de Zaragoza, Spain) for the valuable comments and constructive suggestions on this manuscript.

\section{References}

Amin, O.M., Sonenshine, D.E., 1970. Development of the American dog tick, Dermacentor variabilis, following partial feeding by immatures. Ann. Entomol. Soc. Am. 63, 128-133.

Bechara, G.H., Szabó, M.P.J., Ferreira, B.R., Garcia, M.V., 1995. Rhipicephalus sanguineus in Brazil: feeding and reproductive aspects under laboratorial conditions. Rev. Bras. Parasitol. Vet. 4, 61-66.

Black 4th, W.C., Piesman, J., 1994. Phylogeny of hard- and soft-tick taxa (Acari: Ixodida) based on mitochondrial $16 \mathrm{~S}$ rDNA sequences. Proc. Nat. Acad. Sci. U. S. A. 91, 10034-10038.

Camicas, J.L., Hervy, J.P., Adam, F., Morel, P.C. (Eds.), 1998. Les tiques du monde. Editions de líOrstom, Paris, 223 pp.

Chilton, N.B., Gasser, R.B., Beveridge, I., 1995. Differences in a ribosomal DNA sequence of morphologically indistinguishable species within the Hypodontus macropi complex (Nematoda: Strongyloidea). Int. J. Parasitol. 25, 647-651.

Dantas-Torres, F., Latrofa, M.S., Annoscia, G., Giannelli, A., Parisi, A., Otranto, D. 2013. Morphological and genetic diversity of Rhipicephalus sanguineus sensu lato from the New and Old Worlds. Parasites Vectors 6, 213.

Dantas-Torres, F., Otranto, D., 2015. Further thoughts on the taxonomy and vector role of Rhipicephalus sanguineus group ticks. Vet. Parasitol. 208, 9-13.

Dietrich, M., Beati, L., Elguero, E., Boulinier, T., Mccoy, K.D., 2012. Body size and shape evolution in host races of the tick Ixodes uriae. Biol. J. Linn. Soc. 108, 323-334.

Fairbairn, D.J., 1997. Allometry for sexual size dimorphism: pattern and process in the coevolution of body size in males and females. Ann. Rev. Ecol. Evol. Syst. 28, 659-687.

Famadas, K.M., Serra-Freire, N.M., Faccini, J.L.H., 1996. A note on slide-mounting technique of unfed immature stages of Amblyomma cajennense Frabricius, 1787 (Acari: Ixodidae). Mem. Inst. Oswaldo Cruz 91, 139-140.

Gray, J., Dantas-Torres, F., Estrada-Peña, A., Levin, M., 2013. Systematics and ecology of the brown dog tick, Rhipicephalus sanguineus. Ticks Tick-Borne Dis. 4, 171-180.

Guglielmone, A.A., Robbins, R.G., Apanaskevich, D.A., Petney, T.N., Estrada-Peña, A., Horak, I.G., 2014. The Hard Ticks of the World (Acari: Ixodida: Ixodidae). Springer, Dordrecht, 738 pp.

Hall, T.A., 1999. BioEdit: a user friendly biological sequence alignment editor and analysis program for windows 95/98/NT. Nucl. Acids Symp. Ser. 41, 95-98.

Koch, H.G., 1986. Development of the lone star tick, Amblyomma americanum (Acari: Ixodidae), from immatures of different engorgement weights. J. Kansas Entomol. Soc. 59, 309-313.

Koch, C.L., 1844. Systematische Ubersicht uber die Ordnung der Zecken. Arch. Naturgesch. 10, 217-239.

Larkin, M.A., Blackshields, G., Brown, N.P., Chenna, R., McGettigan, P.A., McWilliam, H., Valentin, F., Wallace, I.M., Wilm, A., Lopez, R., Thompson, J.D., Gibson, T.J. Higgins, D.G., 2007. Clustal W and clustal X version 2.0. Bioinformatics 23, 2947-2948.

Latreille, P.A., 1806. Genera crustaceorum et insectorum secundum ordinem naturalem in familia disposita, iconibus exemplisque plurimis explicata. Paris et Argentorati 1, 302.

Levin, M.L., Studer, E., Killmaster, L., Zemtsova, G., Mumcuoglu, K.Y., 2012. Crossbreeding between different geographical populations of the brown dog tick, Rhipicephalus sanguineus (Acari: Ixodidae). Exp. Appl. Acarol. 58, 51-68.

Liu, G.H., Chen, F., Chen, Y.Z., Song, H.Q., Lin, R.Q., Zhou, D.H., Zhu, X.Q., 2007 Complete mitochondrial genome sequence data provides genetic evidence that the brown dog tick Rhipicephalus sanguineus (Acari: Ixodidae) represents a species complex. Int. J. Biol. Sci. 9, 361-369.

Mangold, A.J., Bargues, M.D., Mas-Coma, S., 1998. Mitochondrial 16S rRNA sequences and phylogenetic relationships of Rhipicephalus and other tick genera among Metastriata (Acari: Ixodidae). Parasitol. Res. 84, 478-484.

Moraes-Filho, J., Marcili, A., Nieri-Bastos, F., Richtzenhain, L.J., Labruna, M.B., 2011. Genetic analysis of ticks belonging to the Rhipicephalus sanguineus group in Latin America. Acta Trop. 117, 51-55.

Minelli, A., Fusco, G., 2010. Developmental plasticity and evolution of animal complex life cycles. Philos. Trans. R. Soc. Lond. B. Biol. Sci. 365, 631-640.

Nava, S., Mastropaolo, M., Venzal, J.M., Mangold, A.J., Guglielmone, A.A., 2012. Mitochondrial DNA analysis of Rhipicephalus sanguineus sensu lato (Acari: Ixodidae) in Southern Cone of South America. Vet. Parasitol. 190, 547-555.

Nava, S., Estrada-Peña, A., Petney, T., Beati, L., Labruna, M.B., Szabó, M.P.J., Venzal, J.M., Mastropaolo, M., Mangold, A.J., Guglielmone, A.A., 2015. The taxonomy status of Rhipicephalus sanguineus (Latreille, 1806). Vet. Parasitol. 208, 2-8.

Obenchain, F.D., Leahy, M.G., Oliver Jr., M.H., 1980. Implications of tick size on the quantifications of engorgement in famale Dermacentor variabilis. J. Parasitol. $66,282-286$

Oliveira, P.R., Bechara, G.H., Denardi, S.E., Saito, C.S., Nunes, E.T., Szabó, M.P.J., Camargo Mathias, M.I., 2005. Comparison of the external morphology of Rhipicephalus sanguineus (Latreille, 1806) (Acari, Ixodidae) ticks from Brazil and Argentina. Vet. Parasitol. 129, 139-147.

Pegram, R.G., Clifford, C.M., Walker, J.B., Keirans, J.E., 1987. Clarification of the Rhipicephalus sanguineus group (Acari, Ixodidae). I. R. sulcatus Neumann, 1908 and R. turanicus Pomerantsev, 1936. Syst. Parasitol. 10, 3-26.

Speybroeck, N., Madder, M., Van den Bossche, P., Mtambo, J., Berkvens, N., Chaka G., Mulumba, M., Brandt, J., Tirry, L., Berkvens, D., 2002. Distribution and phenology of ixodid ticks in southern Zambia. Med. Vet. Entomol. 16, 430-441. 
Speybroeck, N., Madder, M., Thulke, H.H., Mtambo, J., Tirry, L., Chaka, G., Marcotty, T., Berkvens, D., 2004. Variation in body size in the tick complex Rhipicephalus appendiculatus/Rhipicephalus zambeziensis. J. Vector Ecol. 29, 347-354.

Szabó, M.P.J., Mukai, L.S., Rosa, P.C.S., Bechara, G.H., 1995. Differences in the acquired resistance of dogs, hamsters, and guinea pigs to repeated infestations with adult ticks Rhipicephalus sanguineus (Acari: Ixodidae). Braz. J. Vet. Res. Anim. Sci. 32, 43-50.

Szabó, M.P.J., Mangold, A.J., Joao, C.F., Bechara, G.H., Guglielmone, A.A., 2005.

Biological and DNA evidence of two dissimilar populations of the Rhipicephalus sanguineus tick group (Acari, Ixodidae) in South America. Vet. Parasitol. 130,

$131-140$
Tamura, K., Dudley, J., Nei, M., Kumar, S., 2007. MEGA4: molecular evolutionary genetics analysis (MEGA) software version 4.0. Mol. Biol. Evol. 24, 1596-1599. Walker, J.B., Keirans, J.E., Horak, I.G., 2000. The Genus Rhipicephalus (Acari: Ixodidae): A Guide to the Brown Ticks of the World. Cambridge University Press, Cambridge, 643 pp.

West-Eberhard, M.J., 2003. Developmental Plasticity and Evolution. Oxford University Press, New York, 794 pp. 